\title{
Tumor epithelial tumors: do we expect a brighter or a grey future?
}

\author{
Rolando M. D’Angelillo, Sara Ramella \\ Radiation Oncology, Università Campus Bio-Medico, Rome, Italy \\ Correspondence to: Rolando M. D’Angelillo. Radiation Oncology, Università Campus Bio-Medico, Rome, Italy. Email: r.dangelillo@unicampus.it. \\ Provenance: This is an invited Editorial commissioned by Section Editor Dr. Gang Shen, MMSC (The Second Affiliated Hospital Zhejiang University \\ School of Medicine, Hangzhou, China). \\ Comment on: Meurgey A, Girard N, Merveilleux du Vignaux C, et al. Assessment of the ITMIG statement on the WHO histological classification and \\ of the eighth TNM staging of thymic epithelial tumors, of a series of 188 thymic epithelial tumors. J Thorac Oncol 2017;12:1571-81.
}

Submitted Sep 15, 2017. Accepted for publication Sep 22, 2017.

doi: $10.21037 /$ jtd.2017.10.30

View this article at: http://dx.doi.org/10.21037/jtd.2017.10.30

Recent years have been very important for thymic epithelial tumors (TETs), due to several joined publications of the International Thymic Malignancies Interest Group (ITMIG) and International Association for the study of lung cancer (IASLC) (1-3). Together ITMIG and IASLC proposed a new TNM classification which was received by AJCC/UICC for the 8th edition of the TNM classification, while ITMIG alone (4) provided some consensus statements on the use of WHO histological classification.

A recent paper by Meurgey et al. (5), analyzing in a retrospective way prospectively recorded data, explores the feasibility and relevance of these two innovations among 188 TETs diagnosed and treated at Louis-Pradel Hospital, Hospices Civils de Lyon.

WHO histological classification has been questioned over time due to the ability of pathologists to well recognized different patterns (6-8): French paper underlines that the major criteria proposed by ITMIG are present in $100 \%$ of analyzed specimens in type $\mathrm{A}, \mathrm{AB}, \mathrm{B} 1$ and $\mathrm{B} 2$ thymomas as well as in $87 \%$ of thymic carcinomas (TCs). These results are certainly a step forward in recognizing different patterns of WHO classification, but not clearly demonstrate any reduction in inter-observer variability (cases were discussed together between a senior and a junior thoracic pathologist) which is up to $22 \%$ between non-expert diagnosis and expert review (9).

Anyway, WHO classification remains a major prognostic factor on time to recurrence (TTR) and is strictly related to stage (more aggressive features are present in more advanced disease).

TNM staging is generally shared as the most reliable prognostic factor among all tumor types. Data from the French trial did not record any difference in TTR or overall survival (OS) using the 8th TNM classification, while Masaoka stage catches some differences in TTR. OS is a questionable end-point particularly in thymoma, thus our reflections will consider the TTR only.

The big change in the 8th TNM classification is the inclusion of both Masaoka stage I and II in stage I, thus unifying encapsulated TETs along with those infiltrating mediastinal fat or mediastinal pleura. The French trial observed a great migration of their cases from more advanced stage as per Masaoka staging system to stage I per TNM classification that finally represents the majority of patients (from $28 \%$ of Masaoka stage I to $84 \%$ of TNM stage I).

If we look to process of invasion of TETs we can consider four layers: (I) capsule or pseudo-capsule; (II) adipose tissue, mediastinal pleura; (III) visceral pleura, pericardium, and great vessels; (IV) lung, hearth, intraluminary growth.

Masaoka staging system includes these anatomical criteria that disappeared in the new TNM. If we think to thymus surrounding tissue, visceral pleura pericardium and great vessels represents the same layers which can be interested just according to different tumor location. The new TNM seems to be more influenced by the ability of surgeons to achieve a $\mathrm{R} 0$ resection than to natural history of TETs.

Moreover, in French trial very few patients were included in TNM stage II (2\%), no one in stage IIIb and $3 \%$ in stage IV disease. These data are similar to those recorded by ITMIG (1), where $82.5 \%$ of patients were classified as stage 
I, only $3 \%$ as stage II, $9.8 \%$ as stage III (but only $0.4 \%$ with stage IIIB disease) and $4.7 \%$ with stage IV disease (4\% with pleural or pericardial involvement).

Both ITMIG and French data suffer from a selection bias because evaluated patients are just those who underwent surgery. Thus, we need to collect data prospectively on those patients who do not receive any surgery for unresectable disease in order to assess their long-term results and prognosis.

The challenge for the near future will be to discriminate different disease among stage I disease and how to transfer old data on adjuvant treatment in such patients. Probably, the way to go will include the adoption of a risk stratification strategy according to stage, histology and R0 resection (10) along with the implementation of national database (11) with data about resected and un-resected patients.

\section{Acknowledgements}

None.

\section{Footnote}

Conflicts of Interest: The authors have no conflicts of interest to declare.

\section{References}

1. Detterbeck FC, Stratton K, Giroux D, et al. The IASLC/ ITMIG Thymic Epithelial Tumors Staging Project: proposal for an evidence-based stage classification system for the forthcoming (8th) edition of the TNM classification of malignant tumors. J Thorac Oncol 2014;9:S65-72.

2. Nicholson AG, Detterbeck FC, Marino M, et al. The IASLC/ITMIG Thymic Epithelial Tumors Staging Project: proposals for the $\mathrm{T}$ Component for the forthcoming (8th) edition of the TNM classification of malignant tumors. J Thorac Oncol 2014;9:S73-80.

3. Kondo K, Van Schil P, Detterbeck FC, et al. The

Cite this article as: D'Angelillo RM, Ramella S. Tumor epithelial tumors: do we expect a brighter or a grey future? J Thorac Dis 2017;9(11):4180-4181. doi: 10.21037/ jtd.2017.10.30
IASLC/ITMIG Thymic Epithelial Tumors Staging Project: proposals for the $\mathrm{N}$ and $\mathrm{M}$ components for the forthcoming (8th) edition of the TNM classification of malignant tumors. J Thorac Oncol 2014;9:S81-7.

4. Marx A, Ströbel P, Badve SS, et al. ITMIG consensus statement on the use of the WHO histological classification of thymoma and thymic carcinoma: refined definitions, histological criteria, and reporting. J Thorac Oncol 2014;9:596-611.

5. Meurgey A, Girard N, Merveilleux du Vignaux C, et al. Assessment of the ITMIG statement on the WHO histological classification and of the eighth TNM staging of thymic epithelial tumors, of a series of 188 thymic epithelial tumors, J Thorac Oncol 2017;12:1571-81.

6. Rieker RJ, Hoegel J, Morresi-Hauf A, et al. Histologic classification of thymic epithelial tumors: comparison of established classification schemes Int J Cancer 2002;98:900-6.

7. Verghese ET, den Bakker MA, Campbell A, et al. Interobserver variation in the classification of thymic tumours--a multicentre study using the WHO classification system. Histopathology 2008;53:218-23.

8. Wang H, Sima CS, Beasley MB, et al. Classification of thymic epithelial neoplasms is still a challenge to thoracic pathologists: a reproducibility study using digital microscopy. Arch Pathol Lab Med 2014;138:658-63.

9. Molina T, Bluthgen MV, Chalabreysse L, et al. Pathological central review of 290 thymic epithelial tumors (TET): The national network RYTHMIC experience. J Clin Oncol 2016;34:abstr 8568.

10. D'Angelillo RM, Trodella L, Ramella S, et al. Novel prognostic groups in thymic epithelial tumors: assessment of risk and therapeutic strategy selection. Int J Radiat Oncol Biol Phys 2008;71:420-7.

11. Basse C, Thureau S, Bota S, et al. Multidisciplinary tumor board decision-making for postoperative radiotherapy in thymic epithelial tumors: Insights from the RYTHMIC prospective cohort. J Thorac Oncol 2017. [Epub ahead of print]. 